\title{
Violência de gênero em debate: uma análise das conversações sobre a lei do feminicídio na fanpage do Senado Federal
}

\section{Carla Candida Rizzotto}

Doutora; Universidade Federal do Paraná, Curitiba, PR, Brasil. carla_rizzotto@yahoo.com.br

\author{
Aléxia Saraiva \\ Mestranda; Universidade Federal do Paraná, Curitiba, PR, Brasil. \\ alexiasrv@gmail.com
}

\section{Resumo}

Este artigo tem como objetivo discutir as estratégias comunicacionais a que recorrem os indivíduos na formulação e na exposição de suas opiniões sobre temas polêmicos, com vistas ao convencimento de seus interlocutores. Situa-se, assim, ao lado da corrente deliberacionista que defende que a chamada "força do melhor argumento" é concepção excludente que acaba por silenciar determinados grupos e propõe que outras formas de comunicação, além da argumentação racional, sejam levadas em conta nos processos deliberativos, permitindo que públicos diferentes discursem a partir dos modos que são mais permeáveis a eles. Neste momento, como tema polêmico, optou-se pela discussão em torno da lei do feminicídio na fanpage do Senado Federal no Facebook. Foram analisados 915 comentários de 17 posts publicados em seis anos. Como resultado, notou-se uma tendência dos usuários emitirem opiniões baseadas em suas próprias percepções sobre o assunto, de forma individual. No campo do debate, predominam réplicas com opiniões divergentes.

\section{Palavras-chave}

Deliberação. Conversação online. Lei do feminicídio. Estratégias comunicacionais.

\section{Introdução}

A democracia deliberativa visa descentralizar as decisões políticas dos meios burocráticos do Estado, através da participação civil (HABERMAS, 1984). De acordo com Gutmann e Thompson (2004), trata-se de uma forma de governo em que cidadãos livres e 
iguais trocam argumentos aceitáveis e acessíveis visando conclusões obrigatórias, mas revisáveis, para todos. Jane Mansbridge (1999) apresenta uma perspectiva ampliada da deliberação, propondo um sistema composto por redes institucionais e informais, inserindo, também, a conversação cotidiana em sua estrutura. Segundo Marques e Maia (2010) a conversação cotidiana, ao possibilitar o compartilhamento de valores entre os indivíduos, aumenta a diversidade de opiniões circulantes e, consequentemente, a qualidade da formulação das opiniões individuais. Além disso, desafia regras, preconceitos e direciona os indivíduos para a melhor maneira de formulação de suas necessidades, sendo estas consequências que normalmente são atribuídas somente às práticas deliberativas formais.

Diante disso, a pesquisa macro ${ }^{1}$ (RIZZOTTO, 2018), da qual este artigo faz parte, tem como foco verificar como se dá a construção do debate online em diferentes arenas que não possuem a deliberação como fim e, por isso, são chamadas por Mendonça, Sampaio e Barros (2016) como "terceiros espaços". Tal construção é percebida a partir de temas polêmicos que buscam influenciar a tomada de decisões políticas. De acordo com os mesmos autores, “[...] apesar da concentração dos estudos nos espaços formais e/ou gestados para discutir política, boa parte da sociabilidade política ocorre fora destes espaços, o que demanda uma expansão dos objetos de estudo." (MENDONÇA; SAMPAIO; BARROS, 2016, p. 40).

Articulam-se, aqui, as proposições de Jurgen Habermas (1984, 1995, 1997, 2003) Iris Young (2001, 2014) e Jennifer Stromer-Galley (2002, 2007), bem como de outros teóricos deliberacionistas (BENHABIB, 2009; GUTTMANN; THOMPSON, 2004; MAIA, 2004, 2008, 2009; MANSBRIDGE, 2007, 2009) que fornecem instrumentos para o entendimento sobre os processos comunicativos da sociedade. A análise de conteúdo será adotada enquanto procedimento metodológico e, para a formulação das categorias, serão consideradas as proposições de Jennifer Stromer-Galley $(2002,2007)$ acerca das conversações cotidianas. Considera-se, ainda, as críticas direcionadas a concepção habermasiana de democracia deliberativa, feitas por Iris Young (2001), que a denuncia por ser enviesada culturalmente e silenciar determinados grupos. A cientista política estadunidense propõe, assim, a democracia comunicativa como alternativa, na qual outras formas de comunicação mais permeáveis aos diferentes grupos são somadas à argumentação (modelo marcado pelo estilo assertivo e confrontacional) no processo de discussão político, quais sejam, a saudação, a retórica e a narração.

\footnotetext{
${ }^{1}$ A pesquisa mencionada, financiada pelo CNPQ envolve, além de sua coordenadora, seis alunos da graduação e uma do mestrado. Iniciada em 2018, busca responder ao seguinte problema: a que estratégias comunicacionais recorrem os indivíduos na formulação e na exposição de suas opiniões sobre temas polêmicos, com vistas ao convencimento de seus interlocutores? Para isso, optou-se por realizar uma análise de conteúdo de comentários postados em vídeos do YouTube, posts no Facebook e publicações do Twitter que tratam dos temas aborto, cotas raciais e lei do feminicídio. Neste artigo, escolheu-se trabalhar com esta última temática por se articular com a pesquisa realizada no âmbito do mestrado de uma das autoras.
} 
Tal análise possibilitará a formulação de hipóteses acerca do papel da interação em curso nos ambientes online e na formação de preferências e opiniões dos indivíduos, o que, consequentemente, dialoga sobre o potencial democrático das redes sociais. Nessa direção, elabora-se uma questão norteadora: a que estratégias comunicacionais recorrem os indivíduos na formulação e na exposição de suas opiniões sobre temas polêmicos, com vistas ao convencimento de seus interlocutores? Esta pesquisa direciona o olhar para os seguintes temas polêmicos: a descriminalização do aborto, a política de cotas raciais nas universidades $^{2}$ e a Lei do Feminicídio. Este artigo, passo inicial da pesquisa, tem como objetivo específico testar a metodologia proposta por meio da análise de 915 comentários de 17 posts sobre a Lei do Feminicídio na fanpage do Senado Federal no Facebook.

A Lei do Feminicídio está posicionada em uma série de conquistas de gênero que, desde os anos 1990, vêm ocorrendo na América Latina, reconhecendo um delito específico na violência contra a mulher (CAMPOS, 2015), a qual tem uma tendência a ser naturalizada ou absolvida por ser vistas como "crime de paixão" (BLAY, 2008, p. 38). Desde os anos 1970, o movimento feminista no Brasil procura modificar a legislação para tornar menos brandas as leis que enquadram esse tipo de violência (CAMPOS; CARVALHO, 2011).

Nesse contexto, foi sancionada em 2006 a Lei n 11.340 (BRASIL, 2006), conhecida como Lei Maria da Penha. Ela possibilitou a criação de artifícios para diminuir a violência doméstica e familiar, criminalizando a violência física, psicológica, sexual, moral e patrimonial. A partir de então, as Delegacias de Atendimento à Mulher começaram a trabalhar em conjunto com o Poder Judiciário, o Ministério Público e a Defensoria Pública para que esse problema social fosse não só identificado como, também, penalizado. Essa lei caracterizou uma mudança fundamental no tratamento da violência doméstica, e foi tida como um exemplo de legislação na área pelas Nações Unidas (CAMPOS; CARVALHO, 2011).

Segundo o Mapa da Violência 2015: homicídio de mulheres no Brasil (WAISELFISZ, 2015), no período de 1980 a 2013, 106.093 mulheres foram vítimas de homicídio. Na última década considerada pela pesquisa, de 2003 a 2013, o número total de homicídios passou de 3.937 para 4.762 . Isso fez com que a taxa nacional subisse de 4,4 por 100 mil mulheres em 2003 para 4,8 em 2013 - um crescimento de 8,8\% na década. Em um contexto internacional, baseado num grupo de 83 países com dados da Organização Mundial da Saúde, o Brasil ocupa a $5^{\mathrm{a}}$ posição.

Tendo em vista os números crescentes e alarmantes, a Lei do Feminicídio é uma vitória no âmbito da luta feminista e demonstra como é importante que a legislação

\footnotetext{
2 Em parceria com o Centro de Computação Científica e Software Livre (C3SL) da Universidade Federal do Paraná e a Secretaria de Políticas de Promoção da Igualdade Racial (SEPPIR) do Governo Federal, no projeto Sistema de monitoramento de políticas de promoção da igualdade racial.
} 
denomine uma violência decorrente de uma desigualdade social. "Nomear a violência feminicida faz reconhecer juridicamente uma forma de violência extrema praticada contra as mulheres e, por isso, simbolicamente importante." (CAMPOS, 2015, p. 114).

Apesar da clara importância desta lei para o combate à violência de gênero, ela não é unanimidade, tanto entre juristas, que consideram a lei como inconstitucional por ferir o princípio de isonomia (MELLO, 2016, p. 107), quanto entre a população em geral. Afinal, não raras vezes, pessoas contrárias a lei a acusam de sexismo por supostamente privilegiar as mulheres. Diante disso, e observando-se o significativo número de comentários na consulta realizada pelo Senado Federal em sua página no Facebook, trata-se de um tema polêmico e frutífero para a discussão acerca das estratégias comunicacionais mobilizadas nos debates online.

\section{0 debate público de razões}

Diversos estudiosos da deliberação propõem diferentes aspectos enquanto composição de seus conceitos. Coincidem as considerações sobre a autonomia dos cidadãos, a acessibilidade, a não-coação, a importância da reflexão e a revisibilidade das decisões. Quanto aos cidadãos, não podem ser considerados como passivos, mas sim agentes autonômos que interferem no processo democrático. É fundamental, também, que tenham acesso à discussão, a qual deve ser pública e atingível no que diz respeito ao seu conteúdo (GUTMANN; THOMPSON, 2004). É por essa razão que os argumentos devem partir de uma perspectiva neutra, válida para todos.

Há, ainda, a necessidade de que o processo esteja livre de coações, sejam elas externas ou internas, o que significa que os participantes, em iguais condições, somente se submetem às regras procedimentais e aos pressupostos comunicacionais (HABERMAS, 1997). A reflexão é valorizada, pois garante que as decisões tomadas sejam resultado da troca de argumentos posta em prática nos espaços deliberativos. De acordo com Maia (2008) isso significa dizer que é a justificação pública que garante a legitimidade ao poder político. Outro elemento essencial é o respeito mútuo, do qual decorre a necessidade de que os participantes estejam disponíveis para mudar o seu posicionamento inicial. Assim, o seu propósito é que sejam buscados pontos de convergência (sempre sujeitos à revisibilidade diga-se) entre questões opostas, evitando possíveis conflitos. Para Guttmann e Thompson (2004) essa união entre diferentes argumentos favorece a deliberação já que 
instructive if taken partially. A democracy can govern effectively and prosper morally if its citizens seek to clarify and narrow their deliberative disagreements without giving up their core moral commitments. (GUTTMANN; THOMPSON, 2004, p. 28).

$\mathrm{Na}$ junção de tais aspectos, decorre o entendimento da democracia deliberativa enquanto modelo político que enfatiza a necessidade de participação da esfera civil nas decisões políticas. Trata-se de um aprofundamento da noção habermasiana de esfera pública, a qual pode ser definida como a busca pela melhor ou mais justa solução através do debate público de razões (HABERMAS, 1997).

Existem, todavia, autores que defendem que devem haver alternativas ao discurso racional na deliberação. É o caso de Dryzek (2007) que acredita que a retórica, a contação de histórias e até mesmo as piadas podem ser aceitas. Mansbridge (2007) defende a importância da emoção no processo de discussão justificando que através delas o sujeito pesa as opções de maneira mais empática. Da mesma forma, Young (2001) propõe que as diferenças culturais ou de perspectiva social sejam compreendidas como recursos da discussão democrática e não como divisões ou problemas a serem superados. Para tanto, ela sugere que outras formas de comunicação mais permeáveis aos diferentes grupos sejam somadas à argumentação no processo de discussão político.

\footnotetext{
Por reconhecer a personificação e as particularidades dos interlocutores, esses três modos de comunicação ajudam a estabelecer e manter a pluralidade que, como tenho defendido, seguindo Arendt, é necessária para o significado e existência da publicidade. Onde o público apresenta diferenças de grupo cultural, de perspectivas sociais e valorativas, essas formas de comunicação suplementam o argumento ao providenciar maneiras de discursar por meio das diferenças na ausência de entendimentos comuns compartilhados. (YOUNG, 2001, p. 380).
}

Essas formas seriam a saudação, pois há a necessidade de se estabelecer confiança e respeito mútuo; a retórica, pois é preciso se fazer escutar; e, por último, a narração, pois a revelação de experiências particulares que não foram vividas pelos outros membros do grupo permite que as histórias de vida tenham igual valor aos argumentos na situação comunicativa.

\section{Conversação política online}

Além de pensar na integração de outras estratégias comunicacionais que não somente a argumentação racional, há também que se ter em vista, se se quer compreender 
as práticas deliberativas, que a discussão para tomada de decisões não se restringe a ambientes institucionalizados (BENHABIB, 2009; MANSBRIDGE, 2009). Trata-se de um "sistema deliberativo ampliado", que, segundo Sampaio, Maia e Marques (2011) é “[...] composto pela conversação entre representantes formais e informais em fóruns públicos, pela conversação entre ativistas políticos, pela conversação cotidiana em espaços privados sobre assuntos públicos e até pela conversação nos media." (SAMPAIO; MAIA; MARQUES, 2011, p. 215, grifo do autor).

Segundo Mansbridge (2009), existem diferenças fundamentais entre a conversação e a deliberação. A primeira não é pensada como uma forma de ação, sendo, portanto, expressiva, enquanto a segunda almeja a ação, ou seja, é intencional, pois visa produzir decisões vinculatórias a toda coletividade envolvida. Mas, apesar das diferenças significativas entre elas, as conversações preparam os cidadãos para as deliberações formais, sendo, assim, fundamentais para a formação da opinião pública (MANSBRIDGE, 2009).

Nessa direção, Maia (2008) explica que “O engajamento dos indivíduos em conversações políticas é importante para o processamento da informação, no sentido de ampliar o entendimento que os participantes têm sobre determinado assunto." (MAIA, 2008, p. 205). E conversa com Marques e Maia (2010):

Conover and Searing (2005) recognize that the practice of deliberation is far more rigorous than informal everyday conversations on issues of public interest. These authors, on the other hand, follow the approach taken by Mansbridge when stating that everyday political conversations, although often disperse in character and weak in deliberative quality, seem to produce certain desirable consequences, namely forming autonomous, informed, and critical citizens. These are consequences often attributed to more rigorous deliberation practices. (MARQUES; MAIA, 2010, p. 615-616).

Mendonça, Sampaio e Barros (2016) ressaltam que a teoria deliberacionista tem dado mais atenção às conversações informais, bem como ao papel da mídia e dos movimentos sociais, "Mais do que enfocar a deliberatividade de uma prática, há uma preocupação em entender a capacidade deliberativa de diversas arenas e suas possíveis contribuições para o fortalecimento da democracia." (MENDONÇA; SAMPAIO; BARROS, 2016, p. 24).

As possibilidades de interação inerentes à internet colocam-na como ferramenta central da participação civil nas democracias contemporâneas. Além disso, a internet possibilita a inclusão de novas vozes na esfera pública, ao oferecer um contexto de engajamento em discussões políticas para aqueles que normalmente não se engajam nas conversações presenciais, seja através de espaços designados para elas ou através de 
espaços nos quais elas acontecem de maneira natural (STROMER-GALLEY, 2002). StromerGalley (2002) recorre aos conceitos goffmanianos de backstage e frontstage para explicar esse fato: quando as pessoas se encontram em público tendem a evitar a discussão política, vista como tabu, mas, quando se percebem em ambientes privados, como o lar e a internet (é o anonimato possibilitado pela internet que faz com que ela seja percebida enquanto tal), se impõem menos restrições à manifestação de suas opiniões. Outras razões seriam a possibilidade de ouvir opiniões diversas e de se manifestar diante de uma audiência:

I posit that people are drawn to political talk online because they have an opportunity to hear diverse opinions. If political talk partners are primarily friends and family, there might not be much diversity of opinion. Online political talk fives one an opportunity to observe a broader range of opinions and arguments. A second reason people may have for engaging in online political talk is that it gives them an opportunity to express their opinion to an audiente of othe people. Online political talk giver one a "soapbox" to express opinions to others who may be quite differente from each other. (STROMER-GALLEY, 2002, p. 33).

Sampaio, Barros e Morais (2012) realizaram um mapeamento das pesquisas no campo da deliberação online procedendo com um levantamento dos critérios utilizados como medição da qualidade da deliberação. As categorias mais frequentes são as que seguem: justificação, ou seja, a sustentação racional dos posicionamentos individuais; reciprocidade, com vistas a construção do consenso leva-se em conta os argumentos apresentados pelos outros participantes; pluralidade, considerando que diferentes pontos de vista devem ser apresentados e avaliados; reflexividade, que representa a reavaliação dos argumentos próprios a partir dos argumentos e experiências alheios; respeito à condição do outro; igualdade entre os participantes, considerados capazes de emitir juízos sobre o tema em debate; informação entendida como “[...] insumo essencial para a construção (e julgamento) de argumentos racionais, lógicos e sustentados na realidade[...]" (SAMPAIO; BARROS; MORAIS, 2012, p. 481); e, por fim, tópico, buscando compreender se os participantes mantém-se no assunto estrutural do debate. Todos estes critérios serão utilizados neste estudo, mas serão integrados a eles a medição das estratégias comunicativas a que recorrem os indivíduos com objetivo de convencimento de seus interlocutores, conforme será detalhado no item a seguir. 


\section{Metodologia}

Jennifer Stromer-Galley (2007) propõe que a análise das conversações online seja realizada tendo em vista a justificação expressa da opinião, a fonte do comentário, a divergência, a igualdade, o tópico e o engajamento. Em pesquisa anterior as categorias propostas foram empregadas na análise de 1079 comentários de seis posts do blog Escreva, Lola, escreva que tratavam de questões de gênero. Os resultados mostraram que a conversação foi marcada pelo desrespeito, menos presente nas conversações face-a-face do que nas conversações online, devido ao anonimato e à distância, características determinantes da interação na internet. Ademais, a análise mostrou um alto índice de divergência, o que é positivo para a deliberação pois estimula os participantes a trabalharem sua argumentação e denotam a presença de engajamento. As discussões se mostraram bastante relacionadas ao tópico central, indicando a articulação de diferentes pontos de vista, o que pode levar à alteração da opinião particular. Além disso, houve baixa incidência de elaboração e alta recorrência a experiências pessoais. (RIZZOTTO, FERRACIOLI, BRAGA, 2017).

Este último resultado direciona ao questionamento sobre a utilização de outras formas comunicacionais que buscam o convencimento, conforme postulado por Young (2001). Por essa razão, às categorias formuladas por Stromer-Galley (2007) embasadas pela teoria habermasiana, serão unidas novas categorias criadas como forma de verificar o uso da saudação, da retórica e da narração nas discussões online.

A primeira variável (V1) refere-se ao tipo de pensamento expresso no comentário. Essa variável também é responsável pela sua divisão em mais de uma categoria de análise, quando necessário. Quer dizer, é possível que um comentário expresse mais de um tipo de pensamento que passa a ser uma unidade de análise independente. 0 diagrama abaixo (Figura 1) ilustra de maneira esquemática o caminho de codificação. 
Figura 1 - Caminho metodológico 1

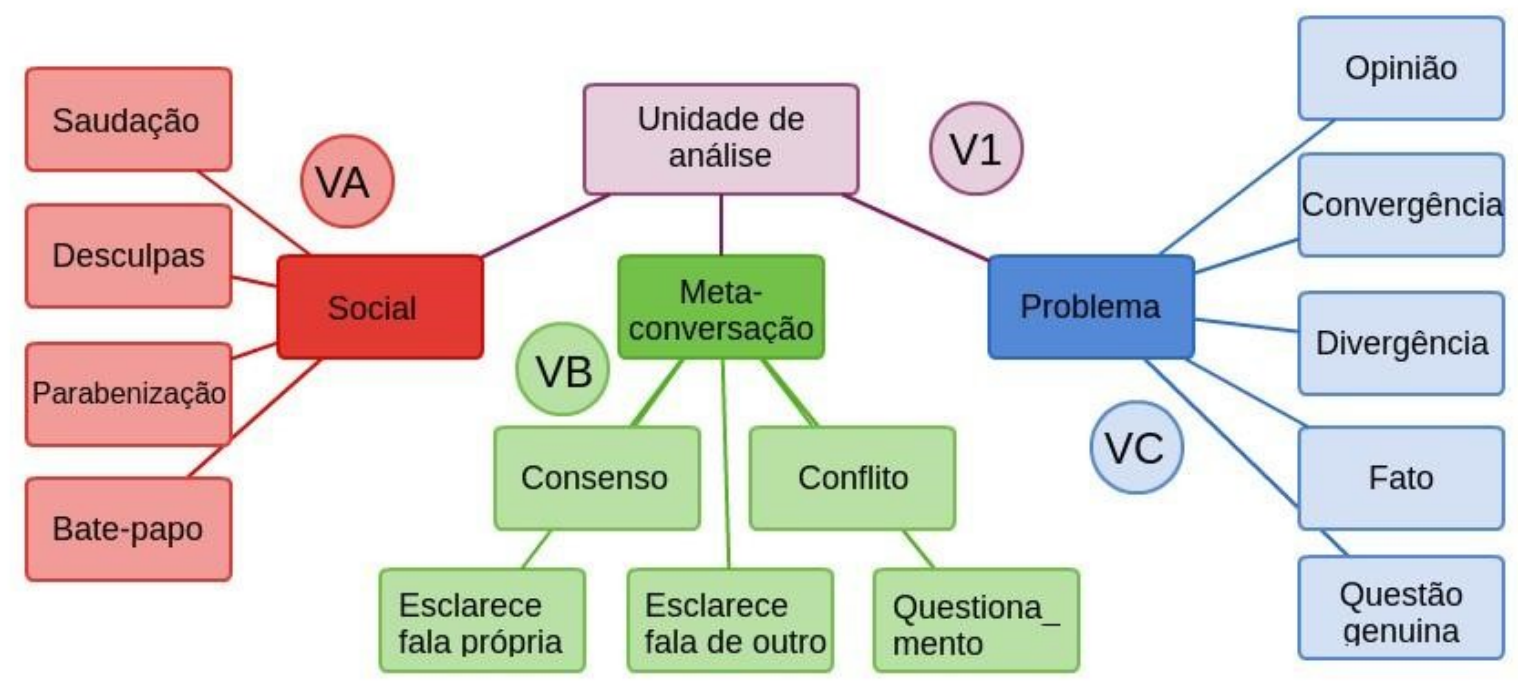

Fonte: Rizzotto (2018).

Os comentários com finalidade relacional são categorizados como social. Nesse caso, há mais uma variável a ser codificada (VA), que trata do tipo de relação estabelecida: saudação, pedido de desculpas, parabenização ou bate-papo. Também podem ser classificados como meta-conversação, quando se referem à própria conversação, tratando da estrutura da fala ou tendo como foco os indivíduos envolvidos no debate e não a temática em si. Da mesma forma que os sociais, os comentários assim classificados, só terão codificada mais uma variável (VB), que determina se se trata de consenso, conflito, esclarecimento de fala própria, esclarecimento de fala de terceiros ou questionamento.

$\mathrm{O}$ último tipo de pensamento (V1) possível é aquele que tem determinado o problema como foco, quer dizer, quando o sujeito expressa sua visão sobre determinada temática, ainda que não diretamente relacionada ao tópico em questão. Nesse caso, o comentário é ainda analisado enquanto opinião, convergência, divergência, fato ou questão genuína (VC).

A partir desse ponto, somente as unidades de análise classificadas enquanto problema terão o turno da fala (VC1), a temática abordada (VC2), a racionalidade (VC3) e a estratégia persuasiva (VC4) analisados. Isso porque (1) as unidades de fala caracterizadas como social e meta-conversação já trazem implícito o engajamento com outrem; e como (2) não contém indicações acerca da temática abordada, (3) não é possível perceber nelas indícios deliberativos para além dos indicativos de civilidade ou incivilidade. 
O diagrama (Figura 2) abaixo ilustra o caminho de codificação das variáveis relacionadas ao problema.

Figura 2 - Caminho metodológico 2

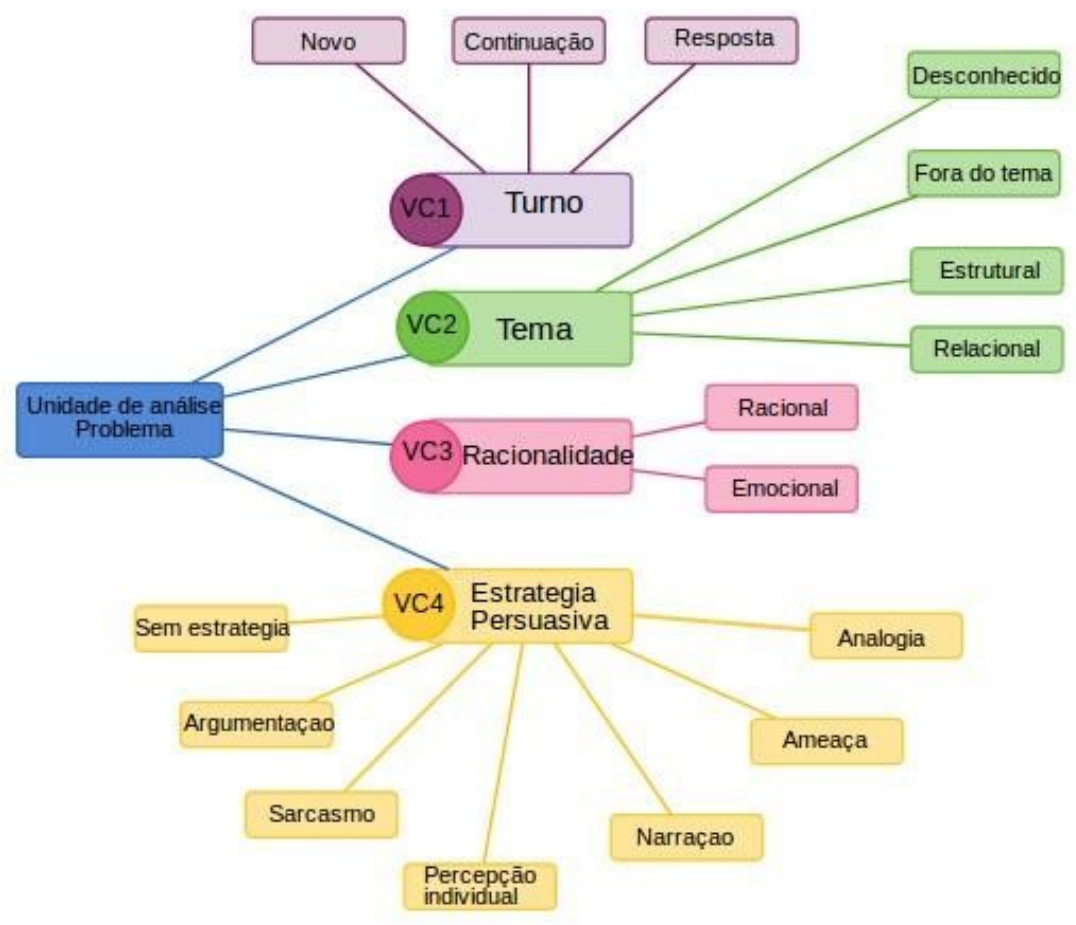

Fonte: Rizzotto (2018).

A reciprocidade será medida pela variável referente ao turno da fala (VC1). Ao saber se o sujeito está elaborando uma fala nova, continuando uma fala própria anterior ou respondendo a outros participantes, é possível fazer inferências acerca do engajamento dos indivíduos no debate, que será positivo caso haja envolvimento em diálogos.

0 tema da conversação (VC2) permite medir o grau deliberativo de um debate, uma vez que, "If the discussion is off topic, then the deliberation cannot meet its objective of deep consideration of an issue." (STROMER-GALLEY, 2007, p. 6). Nesta variável, a codificação se divide em: a) comentários fora do tema; b) comentários estruturais, referindo-se de maneira direta à Lei do Feminicídio; c) comentários relacionais, que tratam temas adjacentes; ou ainda, d) desconhecido, caso não seja possível a identificação do assunto tratado.

A medição da racionalidade (VC3) está relacionada com a justificação expressa da opinião, evidenciada nas asserções verificáveis a partir de evidências. Dessa forma, os textos que ofereciam embasamento classificavam-se como racionais, ainda que fosse ancorado nas experiências pessoais dos participantes. 
A última variável refere-se às estratégias comunicativas empregadas para o convencimento (VC4): sem estratégia; argumentação (utilização de embasamento na elaboração retórica); sarcasmo (que caracteriza um discurso de caráter transgressivo, próximo ao humor); percepção individual (quando se tratam de achismos, ou seja, opiniões pessoais não embasadas); narração (relato de experiências particulares e histórias de vida); ameaça (ou intimidação, ressalta um castigo que o interlocutor receberá caso não compartilhe da mesma ideia do sujeito falante); e analogia (o posicionamento do sujeito é apresentado a partir da correlação de ideias). Esta variável permitirá a verificação de outras formas comunicacionais utilizadas enquanto estratégias de convencimento em conversações sobre temas polêmicos.

Para a análise foram exportados, através do software Socialfy, todos os comentários de posts da página do Senado Federal no Facebook com a temática do feminicídio. A busca com essa palavra-chave resulta em 17 postagens (a primeira datando de 25 de junho de 2013 e, a última, de 14 de março de 2018) que, somadas, englobam 6.400 comentários. Para este universo, a amostragem para uma pesquisa com nível de confiança de 95\% e margem de erro de 3\% deve ser de 915 comentários. Fazem parte do corpus de análise, portanto, os 915 comentários com maior número de réplicas, segundo os dados levantados pelo próprio Socialfy, que correspondem às falas que mais geraram debate entre os usuários nas caixas de comentários.

\section{A Lei do Feminicídio em debate}

"Falam tanto de igualdade e ficam nisso? Uma vida não vale mais que outra". Esse comentário exemplifica a tônica do debate público online em torno da Lei do Feminicídio. 0 principal argumento utilizado pelos contrários à lei acusa-a de ser sexista por valorizar a vida da mulher em detrimento da do homem. Entretanto, para além do posicionamento dos comentaristas, o que nos interessa neste momento da pesquisa é, em primeiro lugar, verificar que tipo de estratégias argumentativas os participantes lançam mão para apresentar seu ponto de vista e convencer seus interlocutores; e, em segundo lugar, compreender se a metodologia desenvolvida para a análise de conteúdo aqui apresentada é adequada, promovendo possíveis alterações nas variáveis utilizadas para a continuidade da pesquisa.

Dos 915 comentários que compuseram a amostra da pesquisa, somente 17,3\% apresentaram o tipo de pensamento (V1) social. Destes, somente 1,94\% eram saudação e 98,06\% eram bate-papo (VA), como, por exemplo: "[nome 1 nome 2 nome 3] a conclusao 
eh q somos prehistoricos". Grande parte deles estabelecia uma conversação com sujeitos que até então não estavam inseridos no debate, utilizando o recurso de marcação da rede social para mostrar o post para amigos ou convidá-los para a discussão.

Os comentários desse tipo têm como objetivo aproximar os sujeitos que se desconhecem a fim de estabelecer laços sociais (STROMER-GALLEY, 2007). Sua utilização vai ao encontro do proposto por Young (2001), a qual defende que a saudação é um sinal de comprometimento com o debate:

Especialmente quando as partes ao diálogo diferem em diversos aspectos, seja em termo de cultura e valores, seja nos interesses e objetivos que pretendem trazer à discussão, seu esforço para resolver conflitos ou chegar a um acordo não pode começar sem preliminares em que as partes estabeleçam confiança ou respeito mútuo. [...] A interação comunicativa em que os participantes almejam o entendimento é frequentemente temperada com gestos de delicadeza e deferência e a ausência deles é interpretada como frieza, indiferença, insulto. (YOUNG, 2001, p. 380-381)

Em VB a meta-conversação apareceu com menor frequência, ainda, apenas em 11,58\% dos comentários, divididos da seguinte forma (VB): (2,29\%) consenso; $(6,66 \%)$ conflito; $(1,3 \%)$ esclarece fala própria; (0,65\%) esclarece fala de outro e $(0,65 \%)$ questionamento. A baixa frequência com que VA e VB aparecem leva a crer que os indivíduos estão pouco interessados na interação com os demais participantes, pelo menos no que tange às interações politizadas. Quer dizer, a amostra analisada deixa ver que os indivíduos utilizam estratégias argumentativas para persuadir os demais, porém, sem se preocupar com os rumos tomados pela discussão. A existência da meta-conversação é um indício de engajamento, conforme explica Stromer-Galley (2007):

\begin{abstract}
Metatalk was viewed as indicating engagement, because meta-talk cannot occur without some reflection on what others have been saying or on what a speaker has said before and which now appears to be misunderstood. Metatalk that clarifies one's own position, for example, occurs only when a participant believes that his prior opinion or question has been misunderstood by at least one other participant. Given such a perceived misunderstanding, clarifying one's position is a signal that there is engagement occurring such that participants are hearing what others are saying and wishing to correct misperceptions of views. (STROMER-GALLEY, 2007, p. 12)
\end{abstract}

A falta de interesse na conversação enquanto processo - que pode ser identificada pelos números apontados nas variáveis descritas anteriormente, bem como na excessiva reincidência de argumentos -, aponta ainda para uma baixa reflexividade, princípio 
normativo da deliberação que prega que os interagentes devem manter seus pressupostos, valores e opiniões abertos ao exame crítico.

O último tipo de pensamento (V1) codificado trata-se daquele focado no problema (VC), que caracterizou a maior parte dos comentários, num total de 84,04\%. Esses comentários foram, em seguida, classificados quanto ao tipo de abordagem, conforme mostra o gráfico (Figura 3) abaixo:

Figura 3 - Tipo de abordagem ao problema (VC)

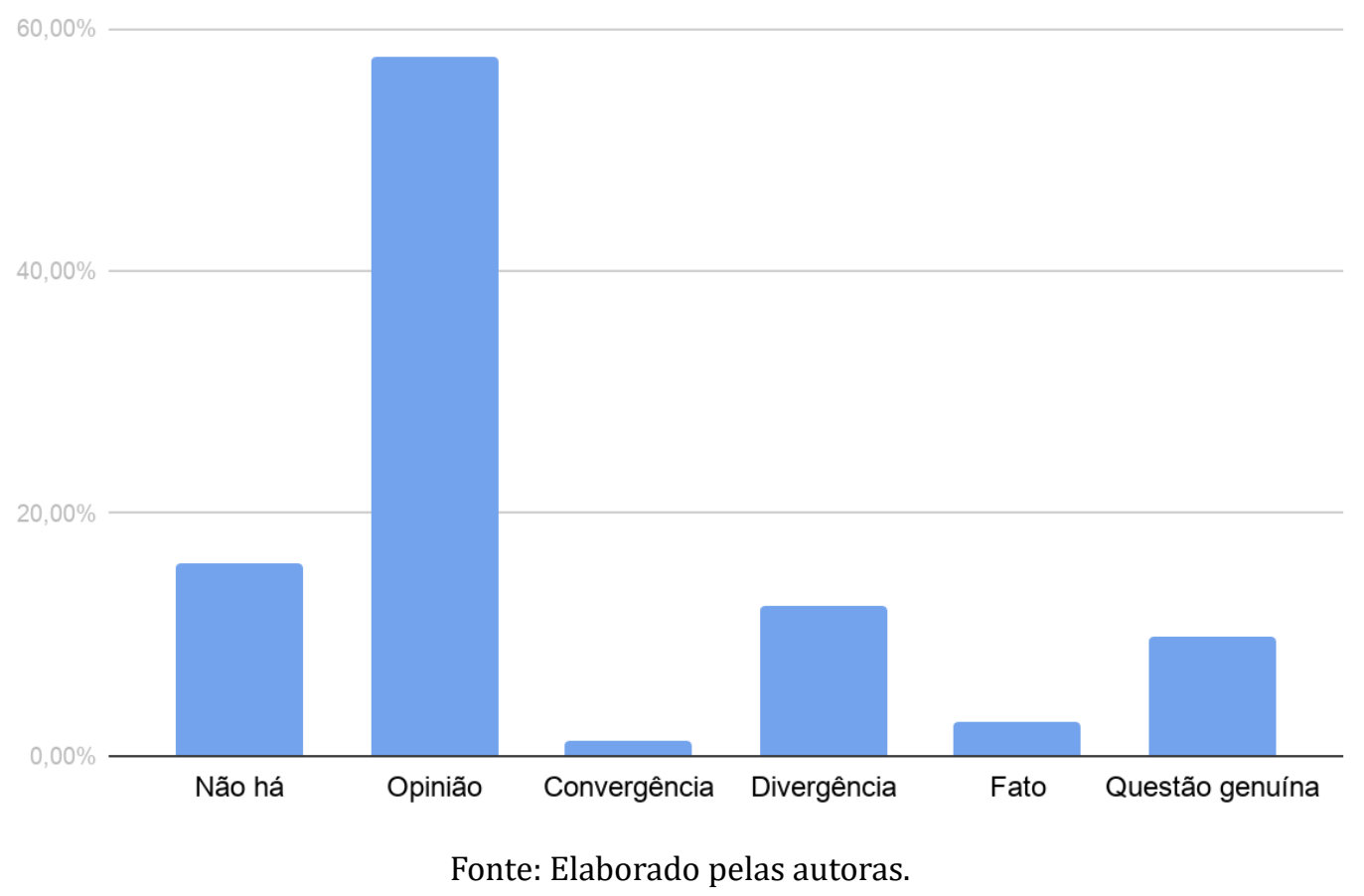

Esta variável (VC) é fundamental enquanto indício para a medição da deliberação, pois permite a verificação acerca da divergência. Segundo Stromer-Galley (2007), a divergência é um sinal da existência de um problema que precisa de uma solução ou de um conflito que demanda uma resolução. Mostra, ainda, que os participantes engajados possuem diferentes pontos de vista, ou seja, há heterogeneidade de perspectivas. Rizzotto, Ferracioli e Braga (2017) falam a respeito da importância deste princípio deliberativo: “[...] o diálogo com outros pontos de vista pode atenuar a polarização das posições políticas, bem como oferece axs participantes a possibilidade de revisão de suas opiniões ou de reforçá-las com argumentos mais racionais." (RIZZOTTO; FERRACIOLI; BRAGA, 2017, p. 363).

Como pode-se notar, a divergência foi bastante frequente na discussão sobre a Lei do Feminicídio, alcançando o índice de 12,34\% dos comentários. Essa divergência apresenta-se 
em relação à opinião dos demais comentaristas e não em relação aos termos da lei ${ }^{3}$, uma vez que pode aparecer, inclusive, em comentários favoráveis:

Ah, realmente, vocês têm razão. 0 fato de violência doméstica ser uma atividade amplamente praticada por homens contra mulheres há séculos não é motivo suficiente pra ser criado um agravante pra que esse tipo de crime não seja visto como algo "comum" aos olhos da sociedade. Quem sofre são os homens que não são protegidos pela lei.

Foi bastante frequente, também, a apresentação de opiniões (57,7\%), como em:

sou mulher, esposa, mãe, avó, e acho absurdo. Homicídio é crime, seja qual for gemero da pessoas. Direitos iguais pra todos. Precisamos de leis mais severas pra acabar violencia. Tirou uma vida, 30 anos enjauladfo, sem nenhum direito, trabalhando pra pagar o que come e sustentar familia que tiver do lado de fora. Não importanto a idade do criminoso, se tem 13, 30, 60 anos. Construir mais cadeia, separadas por genero, e idade, e colocar todo mundo pra trabalhar, e pagar impostos tb. Vão pensar $2 x$ antes de cometerem algum erro. $Q Q$ pena começa com 8 anos de cadeia, sem nenhum direito (roubo, assalto). Estupro = castração quimica mais 30 anos cadeia. Penas leves nao corrige ninguem. Direitos humanos so pra defender pessoa do bem.

Esta variável foi utilizada tendo em vista a tecitura de conclusões acerca da possibilidade de anonimato enquanto ponto crucial para a existência de conflito nas conversações online. Segundo Maia e outros (2016), o anonimato pode contribuir ao mesmo tempo para "[...] aumentar a liberdade de expressão dos sujeitos [e para] facilitar a emergência de comportamentos agressivos." (MAIA et al., 2016, p. 471). Os dados aqui apresentados vão ao encontro da conclusão formulada pelos autores sobre o baixo nível de respeito e reflexividade possibilitado pelo anonimato, uma vez que este tende a distanciar os indivíduos que, por sua vez, acabam por não considerar as opiniões dos demais participantes.

O turno da fala foi medido pela VC1, e pode ser novo $(76,5 \%)$, resposta $(5,79 \%)$ ou continuação de fala anterior (0,22\%). Este dado, a princípio, poderia indicar a inexistência de reciprocidade, porém, para este artigo, esta variável foi medida a partir da ferramenta disponível no Facebook que permite a contabilização de replies. A partir da análise dos dados, todavia, percebemos que essa ferramenta não possibilita uma apreensão correta sobre o turno da fala, uma vez que os usuários podem não possuir domínio da ferramenta. 0 índice anterior que mostrou uma alta divergência entre os participantes fornece indicativos de que, ainda que as opiniões dos demais não sejam apreendidas de modo reflexivo, há uma

\footnotetext{
${ }^{3}$ Quanto aos termos da Lei, a título de curiosidade uma vez que não faz parte dos objetivos dessa pesquisa, verificamos que mais de $60 \%$ dos comentários são contrários a ela.
} 
taxa considerável de conversação. Dessa forma, consideramos que essa variável, assim como as demais, também precisa ser medida mecanicamente para fornecer dados mais exatos.

A maior parte dos comentários (92,9\%) esteve relacionada ao tema (VC2) apresentado na postagem em questão, seja de forma estrutural $(63,93 \%)$ ou relacional $(12,46 \%)$, como no exemplo:

o que é ignorado, é que homens, mulheres, negros, LGBTQs... Todos estes já são vítimas de crimes, de assassinatos, de balas perdidas, de acidentes. Só que além da violência da sociedade... Mulheres são mortas por serem mulheres. LGBTQs são mortos por serem quem são e expressarem sua sexualidade/expressão de gênero. Negros são mortos por serem negros. E várias outras coisas. É por isso que existe a necessidade do agravante, porque tais crimes são crimes de ódio.

De acordo com Stromer-Galley (2007), um alto índice de comentários fora do tema resulta na impossibilidade de racionalização e possível mudança de opinião. Em contrapartida, a recíproca não é verdadeira, já que os resultados aqui apresentados mostram, quando combinados, que mesmo uma boa parte dos comentários relacionando-se com o tema proposto, isso não implica uma reflexividade e revisibilidade de opiniões.

Quanto à racionalidade (VC3), 43,57\% dos comentários são racionais ("0 Feminicidio só vai ocorrer em casos específicos citados no texto, caso a mulher for morta de outra forma é homicídio) e 56,42\% são emocionais

\footnotetext{
(Isso é uma tremenda perda de tempo. Já existe o homicídio. Esses políticos tem é que parar de enrolar e cuidar do que é importante. $\mathrm{E}$ não é o bolso deles! Eu leio essas coisa e tenho até taquicardia de tanta raiva que sinto. ô racinha que gosta de enrolar!)
}

Essa variável se relaciona com a justificação expressa da opinião que, segundo Marques (2011), preconiza que "os pontos de vista devem ser construídos sob a forma de argumentos potencialmente aceitáveis por todos e capazes de ser desafiados e justificados" (MARQUES, 2011, p. 21). Os resultados mostram que a maior parte dos sujeitos não embasa suas opiniões de maneira racional, o que não significa, todavia, que exista prejuízo à deliberação. Essa conclusão aponta que outras formas de comunicação são utilizadas pelos sujeitos para apresentar seus pontos de vista, conforme será verificado na última variável explicada a seguir.

As estratégias persuasivas (VC4), quando existentes (22,8\% dos comentários não apresentaram estratégias de convencimento), foram categorizadas como: argumentação, 
sarcasmo, percepção individual, narração, ameaça e analogia, de acordo com o gráfico (Figura 4) abaixo.

Figura 4 - Estratégias persuasivas presentes na conversação

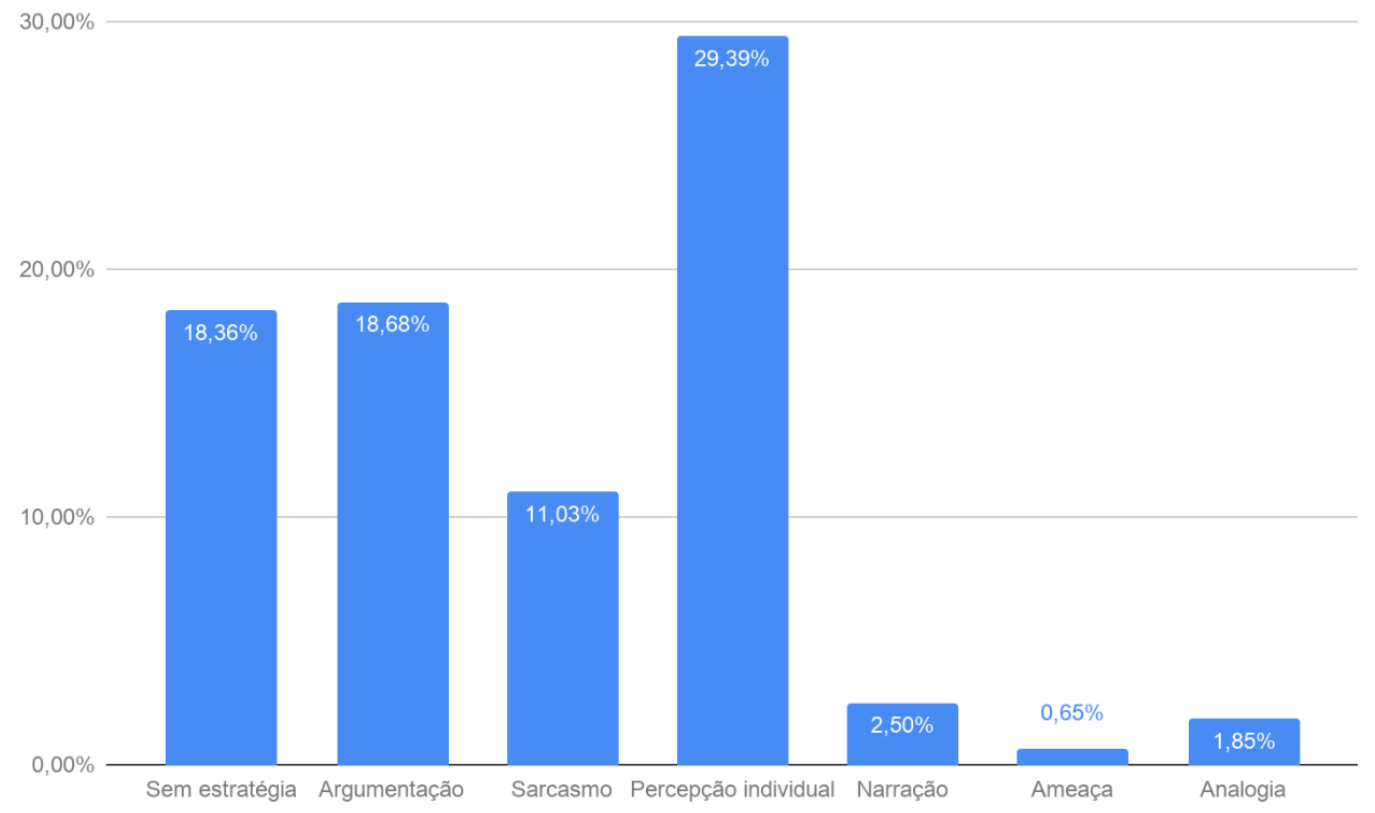

Fonte: Elaborado pelas autoras.

Percepção individual foi a estratégia mais frequente, aparecendo em 29,39\% dos comentários. É exemplo o comentário abaixo que justifica sua opinião a partir de um juízo particular:

Todos os homicídios deveriam ser punidos da mesma forma, uma vida é uma vida. Não importa se é um policial, uma mulher, um homem, uma criança. A minha vida e tão importante pra mim quanto a sua pra você. Sou contra!! Mulheres lutam por igualdade, mas igualdade apenas nas situações a qual elas estão em desvantagem como; igualdade no salário, de igual oportunidades trabalhistas!! Igualdade não é em todos os gêneros? Lutem pelo mesmo fator previdênciário, pelo hominicideo!! Esse tabu que diz que mulher trabalha mais, mulher é dona de casa já não existe mais, os homens modernos trabalham em casa tão quanto as mulheres. Apenas pensam no lado que as doem!! [sic].

Em segundo lugar aparece a argumentação (18,68\%), presente nos casos em que o participante apresenta sua opinião acompanhada de embasamentos, como acontece em: "Temos um índice de solução de crimes de homicídio inferior a 20\%. Enquanto não combater a impunidade, não adianta absolutamente nada aumentar pena". 0 sarcasmo, 
presente no comentário "Noooooossa que ótimo! Depois disso centenas de mortes foram evitadas! Os assassinos sempre refletem e desistem "agora serei punido de verdade". "Milhares de leis prolixas e nenhuma capacidade de julgar e punir severamente, ou seja, a certeza da impunidade!", apareceu em 11,3\% dos comentários, demonstrando que uma parte significativa das discussões online é elaborada de forma provocativa, contendo um teor próximo à zombaria e ao humor. Por último aparecem a analogia $(1,85 \%)$, a narração $(2,5 \%)$ e a ameaça $(0,65 \%)$, exemplificadas respectivamente pelos comentários a seguir:

\begin{abstract}
Ideia utópica de que assassinos se organizam para matar estritamente mulheres pelo fato de serem mulheres. Aconteceu quantas vezes na história da humanidade ? Nenhuma. Faz tanto sentido quanto uma lei pra proteger contra o genocidio do pé grande. Apenas uma lei política inútil pra saciar a doença mental de um determinado público fanático, infantil e egoistinha. $E$ do masculinicidio*, quando será, já tem 5 anos que meu pai foi assassinado e nada do caso resolver, eu não sou mais importante que ele só por ser mulher, inclusive, a "suspeita" de mandar matar ele é mulher (XX), e aí? Como fica? Minha mãe já gastou mundos e fundos correndo atrás e só tava ficando nervosa e perdendo o pouco dinheiro que ganha. Criar é fácil, difícil é fazer valer. Todas essa leis inúteis só servem como cortina de fumaça e tirar atenção do que verdadeiramente interessa. Mas as pessoa já estão acordando e vão acordar muito mais....Só peço a Deus para está viva, pra ver a derrocada de VCs, canalhas! Quero assistir o fuzilamento do meu sofá, comendo pipoca e gargalhando muito!
\end{abstract}

Ainda que os três modos de comunicação apontados por Young (2001), como a retórica (aqui medida pelas variáveis sarcasmo, ameaça e analogia), a narração e a saudação, tenham tido baixa frequência, é significativo que a utilização da argumentação $(18,68 \%)$ foi pouco superior à utilização de outras estratégias persuasivas (somadas, a narração, o sarcasmo, a ameaça e a analogia resultam em 16,03\% da amostra). Isso aponta que a compreensão aprofundada das conversações online sobre temas polêmicos deve levar em consideração uma variedade de formas discursivas, para além da argumentação embasada e racional. Cabe ressaltar, todavia, que a distância entre a temática do feminicídio e a realidade da maior parte dos participantes da conversação pode ser causada pela baixa frequência de experiências pessoais. Nas conversações sobre o aborto (que, por sua vez, serão analisadas na continuidade dessa pesquisa), uma observação inicial já possibilitou verificar que as histórias de vida estão bastante presentes, sejam elas para marcar posição contrária à descriminalização do aborto (com relatos sobre o nascimento dos filhos, por exemplo) sejam 
para marcar posição favorável (com relatos de não-arrependimentos de abortos realizados, por exemplo).

\section{Considerações finais}

Partindo da teoria deliberacionista e da perspectiva que considera que a argumentação racional não deve ser a única forma de justificação considerada enquanto critério da deliberação, este artigo teve como objetivo aferir uma proposta de metodologia para a análise de conversações políticas online acerca de temas polêmicos.

Neste primeiro momento, foram analisados comentários sobre a Lei do Feminicídio em postagens do Senado Federal no Facebook. A análise mostrou que há um baixo índice de engajamento e comprometimento com o debate, isto é, poucos comentários apresentaram preocupação com a discussão enquanto processo, além de que há uma excessiva reincidência de argumentos semelhantes e tampouco houve preocupação em estabelecer laços com os demais participantes. Há, ainda, um baixo índice de respeito e de reflexividade, uma vez que a maior parte dos comentários apresenta a opinião do sujeito desconectada da opinião ou da argumentação dos demais participantes, quer dizer, os indivíduos, na maior parte das vezes falam para si. Os comentários que apresentam divergência (o que, a rigor, é positivo para a deliberação, já que incentiva o sujeito a trabalhar na elaboração do seu ponto de vista) a apresentam de forma conflituosa e desrespeitosa. Vimos, também, que existe uma variedade de estratégias comunicativas utilizadas na exposição das opiniões individuais para além da argumentação, mas que a maior parte dos sujeitos relata simplesmente uma percepção individual. No entanto, isso acontece com teor persuasivo, demonstrando que está correto porque eu penso assim.

A continuidade deste estudo procederá com a análise de comentários sobre outros temas (descriminalização do aborto e política de cotas raciais) em diferentes plataformas (além do Facebook, serão analisados também comentários postados no YouTube e em blogs). A comparação possibilitada por essa análise ampliada enriquecerá a discussão sobre as estratégias comunicacionais que lançam mão os indivíduos nos debates online, permitindo confirmar as ideias aqui expostas que por hora são somente preambulares.

\section{Referências}

BENHABIB, S. Rumo a um modelo deliberativo de legitimidade democrática. In: MARQUES, A. C. S. (org.). A deliberação pública e suas dimensões sociais, políticas e comunicativas: textos fundamentais. Belo Horizonte: Autêntica, 2009. p. 109-141. 
BLAY, A. E. Assassinato de mulheres e Direitos Humanos. Rio de Janeiro: Editora 34, 2008.

BRASIL, Lei no. 11.340. Disponível em: http://www.planalto.gov.br/ccivil_03/_ato20042006/2006/lei/l11340.htm. Acesso em: 4 de nov. 2019.

CAMPOS, C. H. de; CARVALHO, S. Tensões atuais entre a criminologia feminista e a criminologia crítica: a experiência brasileira. In: CAMPOS, Carmen Hein de; CARVALHO, Salo (org.). Lei Maria da Penha comentada em uma perspectiva jurídico-feminista. Rio de Janeiro: Lumen Juris, 2011.

CAMPOS, C. H. de. Feminicídio no Brasil: uma análise crítico-feminista. Sistema Penal \& Violência, Porto Alegre, v. 7, n. 1, p. 103-115, 2015.

DRYZEK, J. Theory, evidence and the tasks of deliberation. In: ROSENBERG, S. W. (org.). Deliberation, participation and democracy: can the people govern? New York: Palgrave Macmillan, 2007.

GUTMANN, A.; THOMPSON, D. Why deliberative democracy? Princeton: Princeton University Press, 2004.

HABERMAS, J. The theory of communicative action: reason and rationalization of society. Boston: Beacon Press, 1984.

HABERMAS, J. Três modelos de democracia. Cadernos do Legislativo, Belo Horizonte, v. 2, n. 3, p. 105-121, jan./jun. 1995.

HABERMAS, J. Direito e democracia: entre facticidade e validade. Rio de Janeiro: Tempo Brasileiro, 1997.

HABERMAS, J. Mudança estrutural da esfera pública. Rio de Janeiro: Tempo Brasileiro, 2003.

MAIA, R. C. M. Dos dilemas da visibilidade midiática para a deliberação pública. In: LEMOS, A. et al. Livro do XII Compós. Porto Alegre: Sulina, 2004. p. 09-38..

MAIA, R. C. M. Conversação cotidiana e deliberação. In: GOMES, W.; MAIA, R. C. M. Comunicação e democracia: problemas e perspectivas. São Paulo: Paulus, 2008. p. 195219.

MAIA, R. C. M. Esfera pública e os media na trajetória de pensamento de Jürgen Habermas. In: MARQUES, A. et al. Esfera pública, redes e jornalismo. Rio de Janeiro: E-papers, 2009. p. 48-69.

MAIA, R. et al. Sobre a importância de se examinar diferentes ambientes on-line em estudos de deliberação a partir de uma abordagem sistêmica. In: MENDONÇA, R. F.; SAMPAIO, R. C.; BARROS, S. A. Deliberação on-line no Brasil: entre iniciativas de democracia digital e redes sociais de conversação. Salvador: EDUFBA, 2016. 
MANSBRIDGE, J. Everyday talk in the deliberative system. In: MACEDO, S. Deliberative politics: essays on democracy and disagreement. New York: Oxford University Press, 1999. p. 211-239.

MANSBRIDGE, J. "Deliberative democracy" or "democratic deliberation"? In: ROSENBERG, S. (org.). Deliberation, participation and democracy: can the People Govern? Basingstoke: Palgrave Macmillan, 2007. cap. 12, p. 251-271.

MANSBRIDGE, J. A conversação cotidiana no sistema deliberativo. In: MARQUES, A. C. S. (org.). A deliberação pública e suas dimensões sociais, políticas e comunicativas: textos fundamentais. Belo Horizonte: Autêntica, 2009. p. 207-237.

MARQUES, A.; MAIA, R. Everyday conversation in the deliberative process: an analysis of communicative exchanges in discussion groups and their contributions to civic and political socialization. Journal of Communication, [s.l.], v. 60, n. 4, p. 611-635, 2010.

\section{MARQUES, A. C. S. Aspectos teórico-metodológicos do processo comunicativo de} deliberação online. Revista Brasileira de Ciência Política, 6, pp. 19-40, 2011.

MELLO, A. R. de. Feminicídio: uma análise sociojurídica da violência contra a mulher no Brasil. Rio de Janeiro: LMJ Mundo Jurídico, 2016.

MENDONÇA, R. F.; SAMPAIO, R. C.; BARROS, S. A. Deliberação on-line no Brasil: entre iniciativas de democracia digital e redes sociais de conversação. Salvador: EDUFBA, 2016.

RIZZOTTO, C. C.; FERRACIOLI, P.; BRAGA, L.. Como elxs discutem questões de gênero? Análise do potencial deliberativo de discussões online sobre feminismo. Contemporanea, Salvador, v. 15, n. 1, p. 352-377, 2017.

RIZZOTTO, C. Racionalidade versus histórias de vida: uma análise das estratégias comunicacionais deliberativas em debates polêmicos e polarizados. [Projeto de pesquisa]. Processo no. 427677/2018-1. Chamada MCTIC/CNPq n.o 28/2018. 2018.

SAMPAIO, R. C.; MAIA, R.; MARQUES, F. P. J. A. Deliberações ampliadas ou restritas: perspectivas de integração. Comunicação \& Sociedade, São Bernardo do Campo, v. 32, n. 55, p. 203-229, 2011.

SAMPAIO, R. C.; BARROS, S. A.; MORAIS, R. Como avaliar a deliberação online? Um mapeamento de critérios relevantes. Opinião Pública, Campinas, v. 18, n. 2, p. 470- 489, 2012.

STROMER-GALLEY, J.. New voices in the public sphere: a comparative analysis of interpersonal and online political talk. The Public, [s.l.], v. 9, n. 2, p. 23-42, 2002. STROMER-GALLEY, J. Measuring deliberation's content: a coding scheme. Journal of Public Deliberation, [s.l.], v. 3, n. 1, p. 1-35, 2007.

WAISELFISZ, J. J. Mapa da Violência 2015: homicídio de mulheres no Brasil. Brasília: FLASCO, 2015.

YOUNG, I. Comunicação e o outro: além da democracia deliberativa. In: Souza, J. (org.). Democracia hoje: novos desafios para a teoria democrática contemporânea. Brasília: UNB, 2001. cap. 12, p. 365-386. 
YOUNG, I. Desafios ativistas à democracia deliberativa. Revista Brasileira de Ciência

Política, Brasília, n. 13, p. 187-212, 2014.

\title{
Gender violence in debate: an analysis of the conversations about the femicide law at the Brazilian Senate's fanpage
}

\begin{abstract}
This article aims to discuss the communication strategies that individuals use in formulating and exposing their opinions on controversial topics, in order to persuate their interlocutors. Thus, it stands next to the deliberationist current that argues that the so-called "force of the best argument" is an exclusionary conception that ends up silencing certain groups and proposes that other forms of communication, besides rational argumentation, should be taken into account in the deliberative processes, allowing different audiences to speak in ways more permeable to them. At this moment, as a controversial topic, we chosed the discussion around the law of feminicide on the Federal Senate fanpage on Facebook. We analyzed 915 comments from 17 posts published in six years. As a result, there was a tendency for users to express opinions based on their own perceptions on the subject, individually. Regarding the field of debate, divergent opinions predominate on the replies.
\end{abstract}

\section{Keywords}

Deliberation. Online Conversation. Feminicide law. Communication strategies. 